\title{
Schooling Beyond COVID-19: An Unevenly Distributed Future
}

\author{
Gavin T. L. Brown* \\ School of Learning, Development \& Professional Practice, Faculty of Education and Social Work, The University of Auckland, \\ Auckland, New Zealand
}

The COVID-19 pandemic crisis has had a major impact on how schooling is done. With schools closed, teaching, and learning continue dependent on information and communication technologies (ICT). To the degree that this has been a success, there is the possibility that post-pandemic societies might choose to de-school, switching to online teaching and learning only. In this perspective piece, I describe two major risks if that future were to be embraced; that is, lack of equitable access and dehumanization. My argument is that these futures already exist in pockets around the globe and we can use those experiences to evaluate those options. I suggest instead that the post-pandemic period gives us an opportunity to re-imagine what schools and schooling are for and advocate for a re-schooled society in which our investment in schools builds and develops society.

\section{OPEN ACCESS}

Edited by:

Canan Blake,

University College London,

United Kingdom

Reviewed by:

Jon Mason,

Charles Darwin University, Australia

Lilly Augustine,

Jönköping University, Sweden

Kathryn Holmes,

Western Sydney University, Australia

*Correspondence:

Gavin T. L. Brown

gt.brown@auckland.ac.nz

Specialty section:

This article was submitted to

Digital Learning Innovations,

a section of the journal

Frontiers in Education

Received: 17 April 2020

Accepted: 19 May 2020

Published: 29 May 2020

Citation:

Brown GTL (2020) Schooling Beyond COVID-19: An Unevenly Distributed

Future. Front. Educ. 5:82.

doi: 10.3389/feduc.2020.00082
Keywords: schooling, future, dehumanization, access, reschooling, de-schooling

William Gibson said in the 1990s "the future is already here, it's just not evenly distributed" (Quote Investigator, 2012). This suggests that, in the diversity of policies and practices around the world in how schooling is done, the future may already exist, quite possibly in another country. Consequently, as we emerge from the impact of COVID-19, it is likely that there will be calls to implement innovations that are already in place elsewhere. While we might imagine schooling beyond COVID-19 as simply a return to the status quo, it is worth considering some of thinking that has already been done on this topic.

Some 20 years ago, OECD (2001) imagined six alternative futures (i.e., 20 years from then; in other words, NOW!) for schooling. These futures revolved around three major trajectories; more of the same, the status quo; a de-schooled society in which schools disappeared; and a re-schooled society in which schools became more than mechanisms for transmitting learning or caring for children. Within each of these options, two variants were proposed, such that six possible futures were imagined. These included under status quo, Scenario 1 of robust bureaucratic school systems and Scenario 2 extensions of the existing market model; under re-schooling, Scenario 3 schools as core social centers, and Scenario 4 schools as focused learning organizations, and under deschooling, Scenario 5 learner networks in a network society and Scenario 6 teacher exodus causing a "meltdown."

The probability and validity of these scenarios is not difficult to imagine. Systematic schooling contributes to efficient development of core literacy and numeracy skills required by complex societies; indeed, dating back to the Babylonian era (Cole, 2010). Thus, whether schools are funded by public resources (Scenario 1) or the market (Scenario 2; Ravitch, 2013), an argument can be made that economic development depends on their existence. It is noteworthy that Scenario 5, through its reliance on contemporary information and communication technologies (ICT), offers a way to fulfill the much earlier call (Illich, 1971) for personalized educational webs as an alternative to the dehumanizing effect of mass schooling seen in Scenarios 1 and 2. It is, perhaps, not going 
too far to see in the American school testing regime a perspective which attributes problems in schooling to teachers who are not accountable for poor learning outcomes (Hershberg, 2002; Nichols and Harris, 2016) and who consequently needed to be removed (Scenario 6). The more equity driven options of Scenarios 3 and 4 are less frequently observed, though perhaps Finland's school system post-1980 has fulfilled Scenario 4's aims of quality and equality across all social classes (Sahlberg, 2014).

With those in mind, I'd like to consider how our responses to schooling needs during COVID-19 might play out beyond lockdown and pandemic. In this text, I plan to argue that how we have continued schooling during COVID-19 constitutes a strong basis for moving toward a learning networks Scenario 5 solution. As an alternative, I want to draw attention to the more humane solution of expanding the physical and social usage of our schools along the manner of Scenario 3. I base my analysis on a consideration of how these different OECD scenarios are being played out in pockets around the world.

\section{SCHOOLING IN COVID-19}

The most obvious innovation for overcoming the dangers of physical proximity lies in ICT. Myself, I am using downloaded videos, recorded at home mini-lectures, asynchronous conversations by email with students, announcements on our institutional learning management systems, and synchronous lectures to continue my teaching. Those with greater enthusiasm for e-learning and e-teaching may be using a myriad of other applications to deliver, interact, and stimulate student learning. Hence, we are creating fertile grounds for Scenario 5 as we speak.

For each of these instructional acts, students themselves are even more than before relying on online self-guided teaching resources such as Wikipedia or Khan Academy. The use of ICT in many facets of education is not new, though as Cuban (2003) warns us, many of those technologies failed to provide a solution to a real educational problem. In my own field of educational assessment, the New Zealand Assessment Tools for Teaching and Learning (e-asTTle ${ }^{1}$ ) system was designed to link teaching and learning with standardized, diagnostic tests that helped teachers know better who needs to be taught what next (Brown and Hattie, 2012; Brown et al., 2018). The e-asTTle technology delivers online testing in reading, writing, and mathematics with item response theory scoring and the option of computer adaptive sequential testing (Luecht et al., 2006) and links users to an online repository of curriculum-indexed teaching resources, entitled What Next?

During the pandemic, in New Zealand, official Learning at Home materials ${ }^{2}$ include those created by government agencies (e.g., the Home Learning TV channel; the Ministry of Māori Development funded afedsquad.co.nz), non-government agencies (e.g., storytime.rnz.co.nz; playcentre.org.nz; nzmaths.co.nz) or by private sources (e.g., Joy Business Academy's tycoon games and Genesis Energy's school gen science activities). Hence, we can see a blend of ICT mediated

\footnotetext{
${ }^{1}$ http://e-asttle.tki.org.nz/

${ }^{2}$ https://learningfromhome.govt.nz/
}

resources delivered by television, radio, and internet to meet the needs of students. Further evidence for both Scenario 2 (market driven schooling) and Scenario 5 (network learning).

It is not a surprise to see that the educational needs are being provided through a blend of public and private resources. No one is going to object to private enterprise exercising social responsibility by funding or supplying materials to supplement the school's repertoire of educational materials. Across the schooling sector there are hundreds of companies and organizations providing online resources ${ }^{3}$. In the field of testing, technologies already exist in the marketplace that administer student assessments online (often promising personalized adaptation). Further, the systems provide feedback and diagnosis of learning needs, as well as pointing teachers and learners to next learning steps (von Davier et al., 2019). The more sophisticated systems allow teachers to monitor and interact with students' online learning activities.

However, it is worth considering whether private providers are distorting school knowledge for their own marketing goals. For example, Powell (2014) describes how corporate sponsorship of health curriculum resources appears to function more as advertising than actual health knowledge. It has been argued cogently, by Lingard and Lewis (2016) and others (e.g., Adamson et al., 2016), that as private sector companies (e.g., publishing companies) dominate global education reform movements, they will have an increasing say in how school content is defined, disseminated, and assured. Likewise, when the private sector claims to meet the goals of schooling more efficiently and effectively than public schools, it becomes increasingly likely that tax-based funding becomes an income stream for private sector entrepreneurs (Glass, 2008; Ravitch, 2013); the Scenario 2 future that is already happening, especially in the United States.

\section{SCENARIO 5: THE LIKELY SCHOOLING FUTURE?}

The success of ICT networked learning is evident to some parents who see that their children have been profitably engaged in extensive and rapid learning without the distraction of classmates, the intervention of teachers, or the disruption of bells. Such parents, after the pandemic, in light of the success of their students learning from home by ICT, will question return to school, much as Illich (1971) wanted. Indeed, the capacity of these technologies to bridge the gaps between testing, teaching, curriculum, and learning will support arguments that learning is better with physical distance and ICT than with human teachers in classrooms. With this reasoning, the argument becomes clear that societies should embrace Scenario 5 of deschooled network learning.

While the parent of a child who is flourishing in this homeschooled, independent learning might welcome continuation, such a stance requires the luxury of resources that permit the child to have access to ICT and suitable supervision. Hence, an unacceptable consequence for an open and democratic society in

$\overline{{ }^{3} \mathrm{https} / / / \mathrm{www} . w e a r e t e a c h e r s . c o m}$ /free-online-learning-resources/ 
moving to a Scenario 5 de-schooled, ITC system of schooling is that, like the future, access to these technologies is not equally distributed. Given the speed with which ICT technologies (both hardware and software) change continually meeting those needs over the long-term could be expensive, although like electricity, ICTs are becoming cheaper per unit as they become ubiquitous (Pinker, 2018). While some governments are, under COVID-19 urgency, delivering computers and broadband to all who don't already have those resources, continually meeting those needs may become a political hard sell. Indeed, as Glass (2008) makes clear with examples from the United States it can be difficult to persuade the wealthy to pay for resources that do not directly benefit their own families and communities. Consequently, if all residents are entitled to have these technologies, democratic governments are likely to raise taxes and redistribute spending to meet those needs, reinforcing Scenario 1. In contrast, financial responsibility could be devolved to the individual, as can be seen in market-driven emphases of Scenario 2 already evident in the United States (Glass, 2008; Ravitch, 2013). In their current reality (and possibly our future), individuals who can't pay for technology or educational resources will be left behind. The COVID-19 pandemic has made clear that educational resources include access on demand to a machine and undisrupted access to a quiet space in domestic situations; those without will be left behind. This reality alone should give us pause in considering seriously the legitimacy of Scenario 5 as the basis for what schools beyond the pandemic could do and be.

My second concern with Scenario 5 is that we humans are social and develop by interaction with each other in the material, corporeal world. The negative side-effects of isolation during the COVID-19 lockdown shows how much we need to interact and be with each other, and this is especially true for our children and grandchildren. Real-world interaction is enjoyable and pleasurable, as well as being developmental. Human children learn to be intelligent, empathic, and considerate through interaction with adults and peers (Rogoff, 1991). Thus, interaction within the family and beyond is essential for humanity as we know it. Reducing schooling to interaction with a computer, along the lines of Scenario 5, limits the opportunity to learn important human skills and attributes (e.g., kindness, humility, sharing, support, etc.). We are flesh beings whose identity and culture and our greatness depends on how we interact with each other in the real world. Moving to a de-schooled ICT mediated education seems to be contraindicated. Asimov's 1954 speculative fiction short story The Fun They Had reveals brilliantly the importance of schooling as a human enterprise:

She was thinking about the old schools they had when her grandfather's grandfather was a little boy. All the kids from the whole neighborhood came, laughing and shouting in the schoolyard, sitting together in the schoolroom, going home together at the end of the day. They learned the same things so they could help one another on the homework and talk about it.

And the teachers were people... (Asimov, 1954, p. 127).

I do not want this taken away from us, our children, and grandchildren. I accept that online meetings are much more convenient than traveling, parking, and being exposed to infectious diseases. As toolmakers, it is important that we exploit ICT as a supplement to our culture, but replacing human to human schooling seems contraindicated. But perhaps my fear of Scenario 5 is overstated, in that our ingenuity to create artificial intelligence programming has not yet reached the point in which machines can mimic humanity. If that ever comes in what Kurzweil (2005) anticipates as the Singularity, I am doubtful that we should want that stage of "human" development.

\section{SCENARIO 3: A BETTER FUTURE?}

The current COVID-19 crisis becomes an opportunity to create a re-schooled society (Scenario 3) instead of the dark future I see in Scenario 5. This scenario seeks to put the whole human at the center of public investment in schooling. This is an easy priority for New Zealand in light of the indigenous Mãori proverb that repeats three times that people are the most important:

\section{He aha te mea nui o te ao}

He tangata, he tangata, he tangata

What is the most important thing in the world?

It is the people, it is the people, it is the people

One way to respond to COVID-19 is to place humans at the center of schooling; to revise schools as core social centers so that there is integration of learning, employment, welfare, and health services for the benefit of all. In this approach, current practices ${ }^{4}$ meet the well-being needs of children and young people by providing such diverse services as breakfast and lunch, health and counseling services, and life skills education on campus. In this fashion, schools are more than learning hubs, they are social centers. Indeed, there are instances of this future already extant; for example, here in New Zealand, the urban Maori development Te Whānau o Waipareira ${ }^{5}$ integrates services covering health, housing, social justice, and education. This pocket of Scenario 3 suggests directions that merit serious consideration if we wish schooling to meet the needs of all.

In line with Scenario 3, post-pandemic, the physical plant of schools, which are spread throughout communities, could become social resources beyond conventional school hours. Schools have large and small meeting places, technologies, artistic and creative spaces and materials, and equipment and facilities for sport, cooking, and making with hard and soft materials. That physical plant is a major public investment that tends to be under-utilized for many hours of the evening and weekends. Those resources, if opened to families and neighbors could make schooling a new center of social good; imagine learning to cook together, a nurse providing clinical care for families, opportunities to create art, learn how to drive, and so on. School campuses, instead of being silent at night with prowling security guards, could become hubs for human interaction, support, and development. Our community libraries are already popular places; they are warm, quiet, have desks, free internet and power, offer opportunities to meet and greet friends and neighbors, as

\footnotetext{
${ }^{4}$ https://www.education.govt.nz/our-work/overall-strategies-and-policies/ wellbeing-in-education/

${ }^{5} \mathrm{https}$ ///www.waipareira.com/free-services-for-you-and-your-whanau/
} 
well as a place to pick up a good read. How much more could our schools do with all that we have already invested in them?

Note that this scenario is not anti-ICT; it is rather an environment in which ICT serves human priorities allowing better human-to-human interaction across the tyranny of distance and time zones or allowing creativity to be exhibited in new ways through interesting combinations of live, 2-D, and 3-D static and moving materials. Many of these ICT tools exist in schools and are often paid for by parental communities in any case. Allowing for a more sophisticated human-ICT interaction within Scenario 3 seems like a desirable outcome post-COVID-19.

Naturally, there are obstacles to overcome in converting schools into social centers, including how to protect educational and curricular materials that schools house while allowing the physical plant to be used for new additional services. Nonetheless, the negative aspects of isolation during pandemic

\section{REFERENCES}

Adamson, F., Åstrand, B., and Darling-Hammond, L. (Eds.). (2016). Global Education Reform: How Privatization and Public Investment Influence Education Outcomes. New York, NY: Routledge.

Asimov, I. (1954). Oh the fun they had. Fantasy Sci. Fiction 6, 125-127.

Brown, G. T. L., and Hattie, J. A. (2012). "The benefits of regular standardized assessment in childhood education: guiding improved instruction and learning," in Contemporary Debates in Childhood Education and Development, eds S. Suggate and E. Reese (London: Routledge), 287-292.

Brown, G. T. L., O’Leary, T. M., and Hattie, J. A. C. (2018). "Effective reporting for formative assessment: the asTTle case example," in Score Reporting: Research and Applications, ed D. Zapata-Rivera (New York, NY: Routledge), $107-125$.

Cole, M. (2010). What's culture got to do with it? Educational research as a necessarily interdisciplinary enterprise. Educ. Res. 39, 461-470. doi: 10.3102/0013189X10380247

Cuban, L. (2003). Oversold and Underused: Computers in the Classroom. Cambridge, MA: Harvard University Press.

Glass, G. V. (2008). Fertilizers, Pills, and Magnetic Strips: The Fate of Public Education in America. Charlotte, NC: Information Age Publishing.

Hershberg, T. (2002). "Comment," in Brookings Papers on Education Policy, ed D. Ravitch (Washington, DC: Brookings Institution Press), 324-333.

Illich, I. (1971). Deschooling Society. New York, NY: Harper.

Kurzweil, R. (2005). The Singularity is Near: When Humans Transcend Biology. New York, NY: Viking Penguin.

Lingard, B., and Lewis, S. (2016). "Globalization of the Anglo-American approach to top-down, test-based educational accountability," in Handbook of Human and Social Conditions in Assessment, eds G. T. L. Brown and L. R. Harris (New York, NY: Routledge), 387-403.

Luecht, R., Brumfield, T., and Breithaupt, K. (2006). A testlet assembly design for adaptive multistage tests. Appl. Meas. Educ. 19, 189-202. doi: 10.1207/s15324818ame1903_2

Nichols, S. L., and Harris, L. R. (2016). "Accountability assessment's effects on teachers and schools," in Handbook of Human and Social Conditions could perhaps be mitigated if we take up the challenge of meeting and being with each other. It is interesting that across the world, we are seeing many instances in which humans are behaving well toward each other. This gives me hope that, instead of embracing the isolation of the machine (Matrix anyone?), we will instead use the future of schools as a method of engaging more profoundly with each other. The intensity of our lock-down and the power of this pandemic disease to scare and kill us, just might make us rethink what schools are for. The goal for me is to ensure that through schools and schooling we make the future accessible to all, not just the privileged.

\section{AUTHOR CONTRIBUTIONS}

The author confirms being the sole contributor of this work and has approved it for publication.

in Assessment, eds G. T. L. Brown and L. R. Harris (New York, NY: Routledge), 40-56.

OECD (2001). What Schools for the Future? Retrieved from: https://www. oecd-ilibrary.org/education/what-schools-for-the-future_9789264195004-en (accessed May 25, 2020).

Pinker, S. (2018). Enlightenment Now: The Case for Reason, Science, Humanism, and Progress. New York, NY: Penguin Random House.

Powell, D. (2014). "The corporatization of health education curricula: 'Part of the solution' to childhood obesity?” in Health Education: Critical Perspectives, eds K. Fitzpatrick and R. Tinning (Oxon: Routledge), 142-156.

Quote Investigator (2012). The Future has Arrived - It's Just Not Evenly Distributed Yet. Retrieved from: https://quoteinvestigator.com/2012/01/24/ future-has-arrived/ (accessed May 25, 2020).

Ravitch, D. (2013). Reign of Error: The Hoax of the Privatization Movement and the Danger to America's Public Schools. New York, NY: A. E. Knopf.

Rogoff, B. (1991). "The joint socialization of development by young children and adults," in Learning to Think: Child Development in Social Context 2, eds P. Light, S. Sheldon, and M. Woodhead (London: Routledge), 67-96.

Sahlberg, P. (2014). Finnish Lessons 2.0: What Can the World Learn From Educational Change in Finland? New York, NY: Teachers College Press.

von Davier, A. A., Deonovic, B., Yudelson, M., Polyak, S. T., and Woo, A. (2019). Computational psychometrics approach to holistic learning and assessment systems. Front. Educ. 4:69. doi: 10.3389/feduc.2019.00069

Conflict of Interest: The author declares that the research was conducted in the absence of any commercial or financial relationships that could be construed as a potential conflict of interest.

Copyright (C) 2020 Brown. This is an open-access article distributed under the terms of the Creative Commons Attribution License (CC BY). The use, distribution or reproduction in other forums is permitted, provided the original author(s) and the copyright owner(s) are credited and that the original publication in this journal is cited, in accordance with accepted academic practice. No use, distribution or reproduction is permitted which does not comply with these terms. 